\title{
English Tense and Aspect: EFL Problems That Chhulung Learners Have
}

Ichchha Purna Rai

\begin{abstract}
The paper deals with English and Chhulung ${ }^{*}$ tense and aspect systems. Tense and aspect are important components in grammar of any language. This paper focuses on the differences between English and Chhulung tense and aspect systems and analyzes the EFL problems of Chhulung learners of English in learning English tense and aspect.
\end{abstract}

Key words:Tense, Aspect, Perfective, Perfect, Past, Non-past, Progressive

\section{The comparison between English and Chhulung tense and aspect}

There are different languages in which tense and aspect are expressed differently. They can be expressed morphologically, lexically and analytically. In some languages, tense is paid more attention rather than aspect because it plays a crutial role in meaning. English is an example of this type. In some languages, aspect is paid more attention rather than tense. Austronesian and African languages are examples of this type (Payne, 2003 p. 234). In polysynthetic languages like Kirati languages of Nepal including
Chhulung, tense is most often associated with the verbal word and in most of the isolating languages, tense is associated with the verbal phrases and tense is marked lexically, morphologically and analytically. Following examples of Englis make it clear that English tense is marked lexically, morphologically and analytically.

The Difference between English and Chhulung tense system

In this section, English and Chhulung tense systems are described first and then difficult area is discussed where the

The Chhulung is pronounced as [ $\left.\mathrm{t}^{\text {sh }} \mathbf{i l i n}\right]$ phonetically but unrounded / $\mathbf{i} /$ is not found in Nepali language so other people call them as saying either Chhulung or Chhiling. Chhulung is both linguistic and ethnic group inhabiting in Akhisalla VDC of Dhankuta, eastern part of Nepal. Chhulung is one of the members of the Kirati language which falls under TibetoBurman language family. It is a lesser-known language since there are not very much extensive works on the Chhulung language. Very few works such as Limbu (2007, 2009 and 2012) and Rai (2007) are examples of the works in the Chhulung language. Chhulung like other Kirati languages is SOV language with complex verbal morphology. It is a pronominalised language with puzzling morphemes in the verbs. The construction of tense and aspect in this language is more interesting and puzzling so these features fascinate the young and enthusiastic linguists. For Chhulung data, I am thankful to Lok Man Rai, Tham Maya Rai, Sleshma Rai, Padam Kumari Rai, Sabhya Rai, Sandesh Rai, Niran Rai and many more of Chhulung speakers during the time of field work (2007-2012). 
Chhulung learnders find it difficult learn English tense.

\section{English tense system}

English tense is not very much complex construction which can be expressed lexically, morphologically and analytically. The following examples make it clear.

1. go $>$ went $=$ lexical (past).

2. a. play $>$ play-ed $=$ morphological (past).

b. plays $>$ play $-s=$ morphological (present).

3. write $>$ will write $=$ analytic (future) .

Three dimensions of time are expressed by two tenses in English, namely past and non-past. They can be shown in a formulaic way in the following figure.

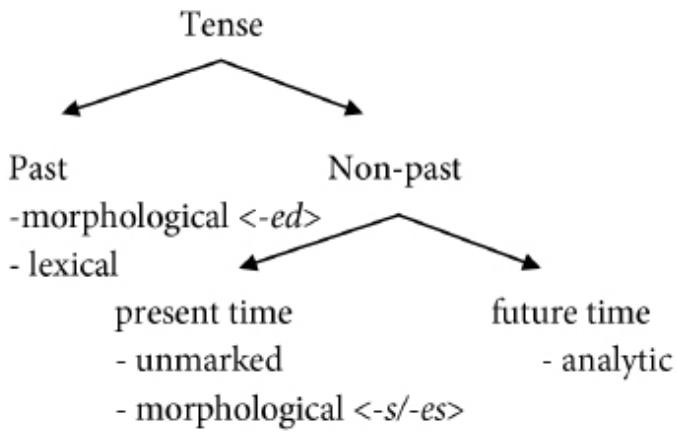

Figure 1: English tense system

In this way, past is expressed both lexically and morphologically, present is expressed morphologically and future is expressed analytically. They can be illustrated by the following examples.

4. They played football (past through morphologically).

5. They went home yesterday (past through lexically).
6. I write a poem (non-past expressing present through unmarked).

7. He writes a poem (non-past expressing present through morphologically).

8. He goes to Kathmandu tomorrow (nonpast expressing future through adverb).

9. He will go to Kathmandu (expressing future through pure model verb).

10. $\mathrm{He}$ is going to go to Kathmandu (expressing future through semimodel verb).

11. He is moving to the UK this winter (expressing future through present progressive)

12. The PM is about to come in Hile (expressing future through 'be about $\left.t o+v^{\prime}\right)$.

13. You are to stay here until 12 o'clock (expressing future through ' $b e t o+v$ ').

Chhulung tense system

Like English, tense in Chhulung is also categorized into past and non-past. There is no future tense in Chhulung. Both past and non-past are expressed through the inflctions in the verbs but there are some differences between English and Chhulung tense system. In Chhulung, past tense refers to the past action or event which is expressed by some morpheme attaching in the verb root as suffix. Morphemes $<-e / a /$ and $h \tilde{e} />$ express the past tense in Chhulung. The past tense suffix $<-e>$ occurs with second person singular $\left(k^{\mathrm{h}} a n\right)$, third person singular (nay), dual (nayk $\left.k^{h} a c^{h} i\right)$ and plural $\left(n a y k^{h} a\right)$ in both transitive and intransitive constructions (Limbu, 2012, p. 25). The following examples illustrate it very clearly.
14. a. $k^{\text {h }}$ an cama th $u k t e$ 
k'han cama $\quad$ thukt-e $^{\text {h }}$

2SG rice 2-cook-PST

You cooked rice.

b. nay cit $^{h}$ i achapte

nay $\quad$ cit $^{\mathrm{i}}$ a-c ${ }^{h}$ apt-e

3SG letter 2-write-PST

$\mathrm{He} /$ she wrote a letter.

Similarly, another past tense marker $<-a>$ in Chhulung occurs to the verb if the first person dual (anchi/anchina) second person dual $\left(k^{h} a n c^{h} i\right)$ and third person dual (nayk $k^{h} a c^{h} i$ ) with transitive and intransitive constructions. The following examples demonstrate it clearly.

15. a. anch $c_{\text {cama } t^{h} u k t a c^{h} e}$

anc $^{h} \mathrm{i}$ cama $\mathrm{t}^{h}$ ukt-a-ch-e

$1 \mathrm{DU}$ rice cook-PST-DU-PST

We (two) cooked rice.

b. $k^{\text {hanch }}{ }^{\text {h }}$ aimsac $^{\text {he }}$

$k^{\text {hanch }}{ }^{\text {h }}$ a-ims-a-c $c^{\text {h }} e$

1DU 2-sleep-PST-DU-PST

You (two) slept.

Similarly, another past tense marker $\langle-h \tilde{e}>$ occurs to the verb if the first person singular (ga), plural (ani / anina) and second person plural $\left(k^{h} a n i\right)$ are subjects in both transitive and intransitive. The following examples demonstrate it clearly.

16. a. $k^{h}$ ani cama $a-t^{h} u k t-i h \tilde{e}$

$\mathrm{k}^{\mathrm{h}}$ ani cam a-t $\mathrm{t}^{\mathrm{h}} \mathrm{ukt}-\mathrm{i}$ hẽ

2PL rice 2-cook-PL-PST

You (all) cooked rice.

b. $k^{h}$ ani aimsihẽ $\mathrm{k}^{\mathrm{h}}$ ani aimsihẽ

2PL 2-sleep-PL-PST

You (all) slept.

Similarly, non-past exrpeses the present action and event which is expressed by several suffixes like $\langle-y u k / k / n u\rangle$. The non-past morpheme $<-y u k>$ occurs to the verb if first person singular, dual, second person dual and third person dual appear as the subject. The following examples demonstrate it clearly.

17. a. anch $i$ imyukch $i$

anc $^{\mathrm{h}_{\mathrm{i}}}$ ims-yuk-c $\mathrm{c}^{\mathrm{h}} \mathrm{i}$

2DU.INCL sleep-NPST-DU

We (two) sleep.

b. anchina-a nay kitab piyukchuna

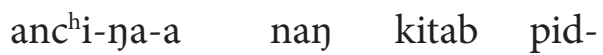
yuk-ch-u-na

2DU-EXCL-ERG 3SG book give-

NPST-DU-3P-EXCL

We (two) give him a book.

The other non-past tense morpeme <-k> occurs in the verb if the first person plural and second person plural appear as the subject. The following examples make it clear.

18. a. ani cama $t^{h} u k t i k i$

ani cama $\quad \mathrm{t}^{\mathrm{h}} \mathrm{ukt}-\mathrm{i}-\mathrm{k}-\mathrm{i}$

2PL rice cook-PL-NPST-PL

We (all) cook rice.

b. $k^{h}$ ani aimsiki

$\mathrm{k}^{\mathrm{h}}$ ani $\mathrm{a}$-ims-i-k-i

2PL 2-sleep-PL-NPST-PL 
You (all) cook rice.

The other non-past tense morpheme $<-$ nu> occurs in the verb if the second person singular and third person singular appear as the subject in both transitive and intransitive constructions. The following examples make it clear.

19. a. $k^{h}$ an cama at $u k n u$

$\mathrm{k}^{\mathrm{h}}$ an cama a-t $\mathrm{t}^{\mathrm{h}} \mathrm{uk}-\mathrm{nu}$

2SG rice 2-cook-NPST

You cook rice.

b. $k^{h}$ an aimnu

khan a-ims-nu

2SG 2-sleep-NPST

You sleep.

Chhulung tense system is puzzling in the sense that there are different morphemes to express the past and non-past tense in different construction. They are shown in the following figure.

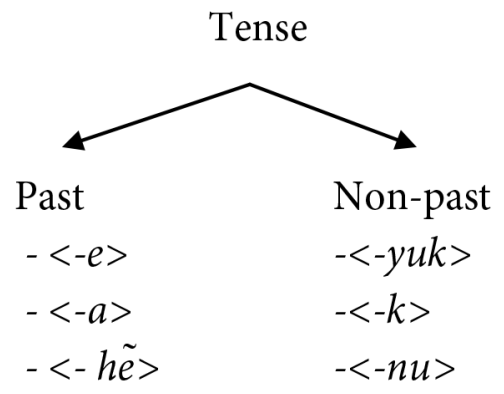

Figure 3: Chhulung tense system

Similarities and differences between English and Chhulung tenses.

Though English and Chhulung have two types of tenses, namely past and non-past, there are some differences in constructions. English tense is expressed lexically [e.g. go= went, put=put], morphologically [e.g. $<-$ ed $>,<-$ s/-es $>$ ] and analytically [e.g. will] whereas Chhulung tense is expressed only morphologically but there are many morphemes which express the past and present/future action. The morphemes like $\langle-\mathrm{e}\rangle,<-\mathrm{a}\rangle,<-$ hẽ $>$ express the past action and the morphemes like $<-\mathrm{a}\rangle,<-\mathrm{k}\rangle$, $<-n u>$ express the present/future action. In English, there are different constructions to express the future action. For examples, they are analytic construction [will] and other types of many constructions [e.g. be going to, be about to, etc.] to express the future action whereas in Chhulung, there is the same construction to express the present and future action some particular time adverbials which show the future are required to express the future action.

\section{The difference between English and Chhulung aspect}

In this section, aspect system found in both English and Chhulung is described and difficult areas for the Chhulung learners is also discussed.

\section{English aspect}

In English, there are only two aspects, viz. perfect aspect and progressive aspect which are represented in the verbs. Two aspects are expressed through auxiliary verbs and the form of main verbs. The progressive aspect which represents ongoing action is structured with be+present participle (-ing) and the perfect aspect which represents action that is complete is constructed with have+past participle (-ed/-en). These two forms of aspect express the aspectual meanings in English. Progressive and perfect aspects are combined to form perfect progressive aspect in English. All of these aspects are combined with the three dimensions of times viz. past, present and future. They can be illustrated by the 
following examples.

20. $\mathrm{He}$ is working (progressive aspect expressing present time).

21. He was working (progressive aspect expressing past time).

22. He will be wroking (progressive aspect expressing future time).

23. He has worked/ he has broken a cup (perfect aspect expressing present time).

24. He had worked/he had broken a cup (perfect aspect expressing past time).

25. He will have worked/ he will have broken a cup (perfect aspect expressing future time).

26. He has been working (perfect progressive aspect expressing present time).

27. He had been working (perfect progressive aspect expressing past time).

28. He will have been working (perfect progressive aspect expressing future time).

In English, there are nine sub-types of aspect which plays an important role in English grammar and sometimes more problematic for EFL students.

Intersection between tense and aspect: Twelve pseudo tenses:

In traditonal grammar, intersection between tense and aspect is treated as tense which is also known as 12 tenses in English. But, they are pseudo tenses in reality which are as follows:

29. He works (tense expressing present time).

30. He worked (tense expressing past time).

31. He will work (tense expressing future time).

32. He is working (progressive aspect expressing present time).

33. He was working (progressive aspect expressing past time).

34. He will be wroking (progressive aspect expressing future time).

35. He has worked (perfect aspect expressing present time).

36. He had worked (perfect aspect expressing past time).

37. He will have worked (perfect aspect expressing future time).

38. He has been working (perfect progressive aspect expressing present time).

39. He had been working (perfect progressive aspect expressing past time).

40. He will have been working (perfect progressive aspect expressing future time).

Chhulung aspect

Chhulung has two aspects which are perfect and progressive. They are described as follows.

\section{Perfect}

Perfect aspect is categorized into two types on the basis of time dimension which are past perfect and present perfect. In Chhulung, past perfect is constructed through complex structure. For past perfective, the present perfect marker $<-a \eta s>$, past tense marker <-a $>$ and possessive marker <-ba> are suffixed to the verb stem gradually and main verb 
is followed by the past form of copula $<y u w a k t e>$ as shown in the following examples.

41. a. ga imsaysaba yuwakte

ga ims-ans-a-ba yuwakte

1SG sleep-PRF-PST POSS

BE.PST

I had slept.

b. khan $c^{h} i t^{h} i$ achaptaysaba yuwakte

khan $c^{h} i t^{h} i \quad a-c^{h} a p-a n s-a-b a$ yuwakte

2SG letter 2-wrte-PRF-PST POSS BE.PST

You had written a letter.

Similarly, present perfect aspect is expressed by $<-a \eta s>$ morpheme which is suffixed to the verb stem. The morpheme $<-a \eta s>$ is followed by the past tense marker $<-h \tilde{e}>$ immediately. It can be illustrated by the following examples.

42. a. ga imsayshẽ

ga ims-aøs-hẽ

1SG sleep-PRF-PST

I have slept.

b. nay habayse

nay hab-ans-e

3SG cry-PRF-PST

He has cried.

\section{Progressive aspect}

Progressive aspect refers to the the an ongoing action of verb in Chhulung which can be categorized int two as past progressive and present progressive in terms of time dimension. They are described below.

In Chhulung, the morpheme <-akt $>$ refers to past progressive aspect which attachs to the verb stem immediately and it is followed by tense and other markers. It is illustrated with the following examples.

43. a. ga cuwa thunaktanhẽ

ga cuwa thun-akt-a-n-hẽ

1SG water drink-PROG-PST-1APST

I was drinking water.

b. gaa cithi chaptaktayhe

ga-a cithi chapt-akt-a-n-hẽ

1SG-ERG letter writePROG-PST1A-PST

I was writing a letter.

Similarly, there are two suffixes $<-y e>$ and $<-e t>$ to represent the present progressive aspect. The suffix $<-y e\rangle$ occurs with intransitive and <-et> occurs with the transitive. The following examples make them clear.

44. a. ga imyerwa

ga ims-ye-rwa

1SG sleep-PROG-1A

I am sleeping.

b. ga cithi chaptetuy

ga cithi chapt-et-u-n

1SG letter write-PROG-3P-1A

I am writing a letter.

Chhulung aspect is complex in construction in comparison to English which can be shown in the following figure clearly.

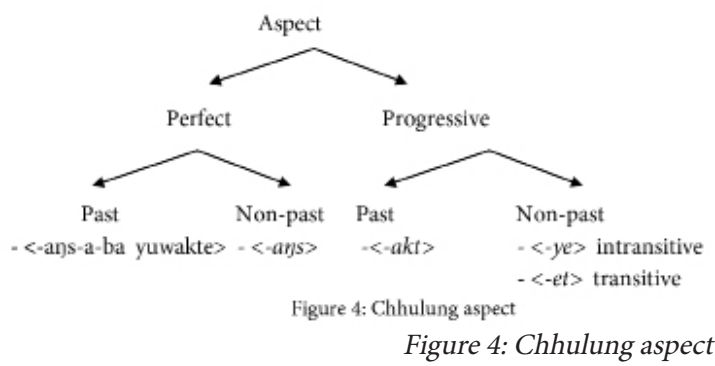


If we intersect both tense and aspect of Chhulung, the following types can be found.

45. Tense expressing past time.

46. Tense expressing present time.

47. Perfect aspect expressing past time.

48. Perfect aspect expressing present time.

49. Progressive expressing past time.

50. Progressive expressing present time.

Similarities and differences between English and Chhulung aspect

In both languages, there are two types of aspect, namely perfect and progressive but they are different in their constructions. An auxiliary verb and a main verb come together to express an aspect in English. The progressive aspect which represents ongoing action is structured with be+present participle (-ing)and a copula $\mathrm{BE}$ verb plays a key role to express three dimensions of time. Similarly, the perfect aspect which represents an action that is complete is constructed with have+past participle (-ed/-en) and an auxiliary verb [HAVE] plays a key role to express different three dimensions of time. On the contrary, an aspect in Chhulung is only morphologically marked except past perfect. There are several morphemes to express an aspect. The morphemes like $[<-$ $a k t\rangle,\langle-y e\rangle,\langle-e t\rangle]$ express the progressive aspect. Similarly, the morpheme like [<ays $>$ ] expresses non-past perfect aspect and the construction like [<-ays-a-ba yuwakte $>$ ] express the past perfect aspect.

\section{Aquisition problems that Chhulung learner as EFL students have}

The construction of the tense and aspect in Chhulung and English are totally different but in both of languages, tense and aspect are expressed through the verb inflections. There are some acquisitonal problems for Chhulung learners as EFL students. They are as follows:

- There are differnt types of consturction of tense in English. They are lexical, morphological and analytic. In Chhulung, there is only one morphological construction to express the tense. Chhulung learners find it difficult to use of lexical construction such as go = went, is = was etc. Similarly, they find it difficult to use non-past tense when they express the present action through present tense since some subjects such as [I, We, You, They] take a bare verb form in which inflection is unmarked and some subjects such as [he, she, it] take inflected verbs ending with either $<-$ s $>$ or $<-$ es $>$. So, they find it difficult to use the alternations of the verb inflections. Similarly, they find it difficult to use the analytic constrution to express the future action. So, these construction should be paid attention towards while teaching English tenses to Chhulung learners.

- In English, future tense is expressed through many types of constructions like pure model verb 'will', 'going to $+v$ ', 'be about to+v' and 'be to+v'. In Chhulung, there is no syntax or inflection to express future tense which is done by using some time adverbials in the present tense. So, Chhulung learners of English find it difficult to express the future action by using correct syntax, verb forms and verb inflections. For example, 
pure modal verbs 'will' and 'be going to $+v$ ' are used to express the future action or event but the former is used to express just probable occurence in future time and the latter is used to express planned activity in future time. In this way, Chhulung learners are not able to make distinction between two concepts of expressing future action or event in future time.

- In Chhulung, tense and aspect can intersect like in English but perfect and progressive aspects do not intersect like they do in English. Consequently, Chhulung learners find it difficult to use the perfect progressive tense expressing past, present and future.

- In English, aspect is expressed through auxiliary verbs and the form of main verbs. The structure of aspect is more complex in comparison to the structure of Chhulung aspect. In English, perfect is constructed through 'have+past participle' and progressive is constructed through 'betpresent participle'. In Chhulung, there are some bound morphemes attached to the main verb which express the both perfect and progressive aspect. These bound morphemes expressing perfect and progressive are influenced by only person marker of subject. So, Chhulung learners find the construction of aspect difficult to use while acquiring the English aspect.

- English has 12 tenses altogether whereas Chhulung has only 6 tenses. At least 12 structures are necessary in English to express the tense and aspect for past, present and future action or event but in Chhulung, there are only
6 structures to express the tense and aspect. There are many structures used to express tenses and aspects in English in comparison to Chhulung. So, Chhulung learners find it difficult to use the tense and aspect correctly. They can face problems especially in the use of future and perfect progressive tenses which are not found in Chhulung.

\section{Conclusion: some pedagogical activities.}

It is challenging to teach English to EFL students. In Nepal, there are no required materials and effective training for teachers to teach English as EFL. To overcome the English tense and aspect system, some pedagogical activities can be conducted as described below. To develop the students' proficiency in tenses and aspects in English, some activities can be adopted. These activities are based on Cowan (2009, p. 385387). First, students should be categorized into different levels like low intermediate, itermediate, high intermediate and advance. The students are asked to describe in simple present such as city or village life where they live or schools/compus where they study or eating habits or daily routines or their personal likes or dislikes. These activities can be done among low intermediate students. They are asked to describe the present situation of weather in present progressive like it's raining, the temperature is increasing etc. Similarly, they are asked to tell a story using simple past such as story about themselves like where were you born, where did you grow up, where did you go to high school or others. They are asked to perform interview such as where was your father working? What were you doing when the bomb exploded? 
This type of interview helps to use past progressive. Teachers can also ask them to make distinction between sentences like $I$ have lived here since 2005. vs. ${ }^{*}$ lived here since 2005. Why is the the former sentence correct and not the latter one?. In this way, students can be engaged in different acitivities such as dialogue, interview, role play, deomonstration, etc. addressing the English tenses and aspects system.

\section{About the author}

Ichchha Purna Rai is the National Chairperson of Indigenous Linguistic Society of Nepal (ILSN) and a former executive member of Linguistic Society of Nepal (LSN). He has a wide range of experiences of Endangered Language Documentation. He has presented several papers in more than a dozen international conferences and has published some articles on the description of endangered languages in national and international journals. Currently, he is involved in teaching graduate and post-graduate courses of English at Dhankuta Multiple Campus, Dhankuta under Tribhuvan University.

\section{Abbreviations}

$$
\begin{aligned}
& 1=\text { first } \\
& 2=\text { second } \\
& 3=\text { third } \\
& A=\text { agent } \\
& \text { DU = dual } \\
& \text { ERG = ergative } \\
& \text { EXCL = exclusive } \\
& \text { INCL = inclusive }
\end{aligned}
$$

NPST $=$ non-past

$\mathrm{SG}=$ singular

$\mathrm{P}=$ patient

$\mathrm{PL}=$ plural

$\mathrm{PRF}=$ perfective

POSS $=$ possessive

$\mathrm{PROG}=$ progressive

$\mathrm{PST}=$ past

\section{References}

Cowan, R. (2009). The teacher's grammer of English: A course book and reference guide. India: Cambride University Press.

Limbu, M. K. (2012). Verb morphology in Chhulung. An unpublished M.A. thesis submitted to the Central Department of Linguistics, T.U. Kirtipur.

---. (2009). Pronominals in Chhulung and English. An unpublished M.Ed. thesis submitted to the Central Department of English Education, T.U. Kirtipur.

---. (2007). An ethnolinguistic observation of Chhulung Rai: A highly endangered language. A report submitted to the social inclusion research fund secretariat (SIRF), SNV. Lalitpur.

Payne, T. E. (2003). Describing morphosyntax: A guide for field linguist. The U.K.:

Cambridge University Press.

Rai, I. P. (2007). Personal pronouns in English and Chhulung: A contrastive study. Journal of NELTA, 12, 102-107. 